\title{
Seismic margin assessment of a reinforced concrete skewed bridge in a nuclear power plant
}

\author{
Tae-Hyung Lee ${ }^{1}$, Van-Hoa Nguyen ${ }^{2,3}$,Van-Tien Phan ${ }^{2}$ and Duy-Duan Nguyen ${ }^{1,2, *}$ \\ ${ }^{1}$ Department of Civil Engineering, Konkuk University, Seoul, Korea \\ ${ }^{2}$ Department of Civil Engineering, Vinh University, Vinh, Vietnam \\ ${ }^{3}$ Moscow State University of Civil Engineering, Yaroslavskoe shosse, 26, Moscow, 129337, Russia
}

\begin{abstract}
This paper presents the seismic margin assessment of a reinforced concrete (RC) bridge using the high-confidence-of-lowprobability-of-failure (HCLPF) value. An existing RC skewed bridge built in a nuclear power plant (NPP) in Korea was selected for studying objective. Finite element modeling of the bridge is developed in OpenSees, an open system for earthquake engineering simulation. The reference earthquakes applied for the probability analysis are selected from the set of generated ground motions that using for designing NPP structures in Korea. The HCLPF value is calculated based on the fragility method associated with the approximate second moment approach. The effect of randomness and uncertainty in demand and capacity variables is taken into account in the fragility analysis procedure. Based on the calculated HCLPF values, the seismic fragility assessment of the bridge can be readily implemented.
\end{abstract}

\section{Introduction}

The seismic safety assessment of the infrastructures is important, particularly the structures within nuclear power plants. In recent time, earthquakes have been occurred in South Korea with a higher level of intensity, such as the 2016 Gyeongju earthquake and the 2017 Pohang earthquake which lately struck Korea in November. Therefore, a seismic fragility assessment of structures in the region is needed. Fragility analysis is a crucial phase and its fragility parameters, obtained from this process play a momentous role for the seismic risk assessment of structures.

Generally, nuclear power plants (NPP) have been designed for the Safe Shutdown Earthquake (SSE) level. In South Korea, the developed response spectrum with the peak ground acceleration (PGA) $0.3 \mathrm{~g}$ is normally selected for designing the SSE. The conservative design criteria are established. Therefore, the NPPs have additional seismic margin to withstand earthquake motion larger than Design Basic Earthquake (DBE) ground motion. For seismic margin assessment, the high confidence of low probability of failure

\footnotetext{
* Corresponding author: duyduan@konkuk.ac.kr
} 
(HCLPF) is utilized to represent the capacity of structures and relays. The HCLPF is defined as the PGA with a $95 \%$ confidence that the probability of failure is less than $5 \%$ point on the fragility curves for a component [1]. There are two methods for computing the HCLPF capacity, the fragility method and the conservative deterministic failure margin method.

For this study, a bridge structure constructed within an NPP in South Korea, is selected for seismic margin assessment. This paper presents the fragility method in terms of approximate second moment approach to calculate the HCPLF of the bridge pier, which is considered as the most crucial member of the bridge structure. The procedure proposed in EPRI (1994) [2] is adopted. The investigated bridge is described in detail in the next section.

\section{Description of the investigated bridge}

The investigated bridge includes 11 spans with the RC slab girder and $10 \mathrm{RC}$ circular threecolumn bent type. The length of all spans is $14.5 \mathrm{~m}$ and the total length of the bridge is $159.5 \mathrm{~m}$. The height of columns is varied from $4.0 \mathrm{~m}$ to $6.0 \mathrm{~m}$, as shown in Fig. 1. The bridge is skewed of $60^{\circ}$, as shown in Fig. 1. The detailed dimensions of the girders, pier columns, and bent-cap are shown in Fig. 2.

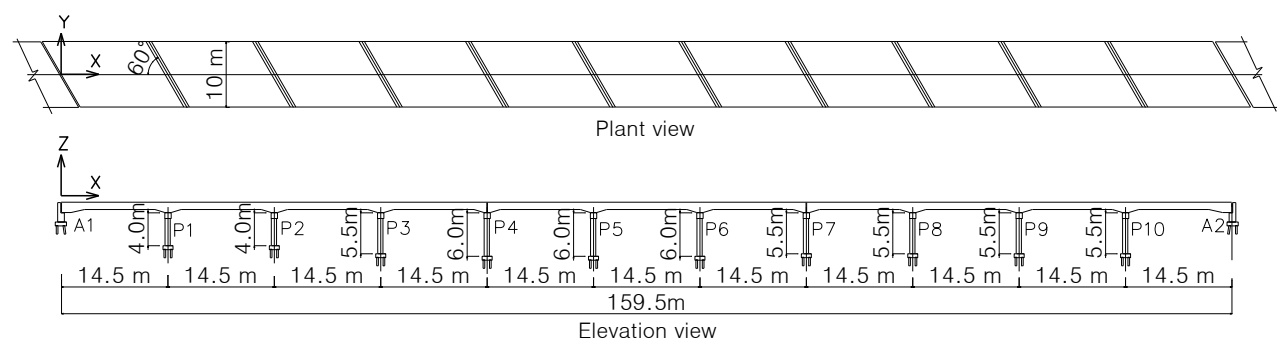

Fig. 1. Configuration of the investigated bridge
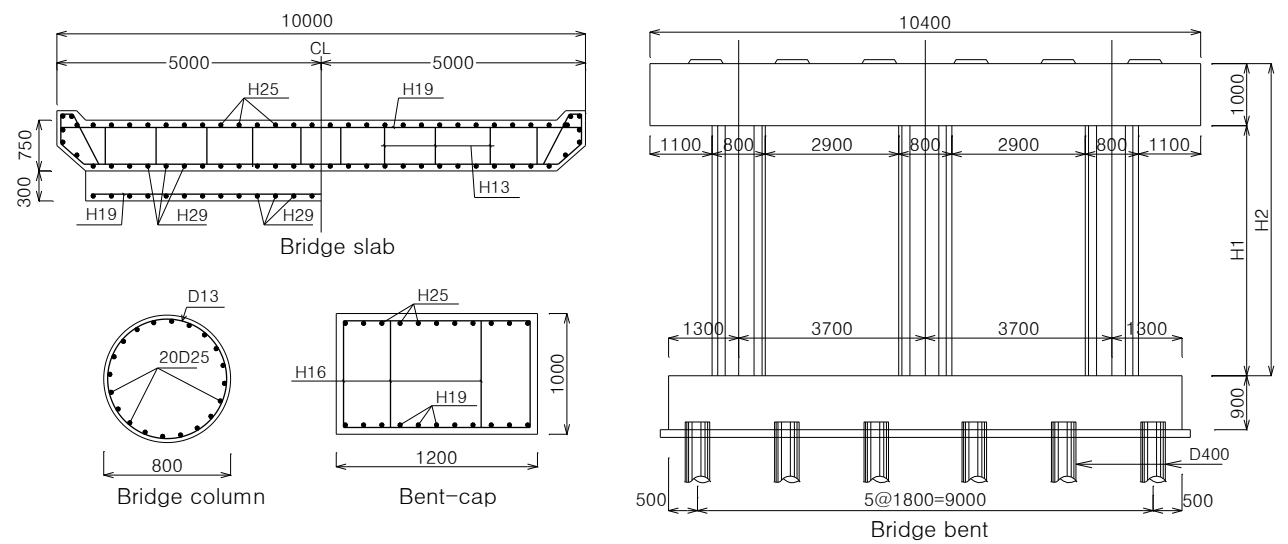

Fig. 2. Cross-section and detail of the structural members 


\section{Numerical modeling}

In this research, the finite element program, OpenSees, is applied for modeling the bridge structure [3]. There are various models for concrete and steel materials in OpenSees. For this research, the concrete02 model, which adopted the Kent-Park model [4] is applied for confined and unconfined concrete of the bridge piers. The steel02 model, which adopted the Menegotto-Pinto model [5] is used for modeling of reinforcing bars. These two models have taken into account the nonlinear characteristics of materials. Fig. 3 shows the stressstrain relationship of the concrete and steel material models. The pier elements are modeled as nonlinear beam column elements in terms of fiber sections. Fig. 4 illustrates the fiber section model for the bridge piers and the moment-curvature relationships of all pier sections.

The girder slab is assumed to be elastic behavior during seismic excitations. Hence, the elastic section namely, ElasticMembranePlateSection, is adopted to model the bridge slab elements. Additionally, the piles are also considered elastic beam elements connected to soil medium through the soil springs. The soil springs are modeled in terms of zerolength elements. The force-displacement relationship of the zerolength is represented by the $p-y$ curves [6]. Fig. 5 shows the 3D finite element model of the bridge in OpenSees.
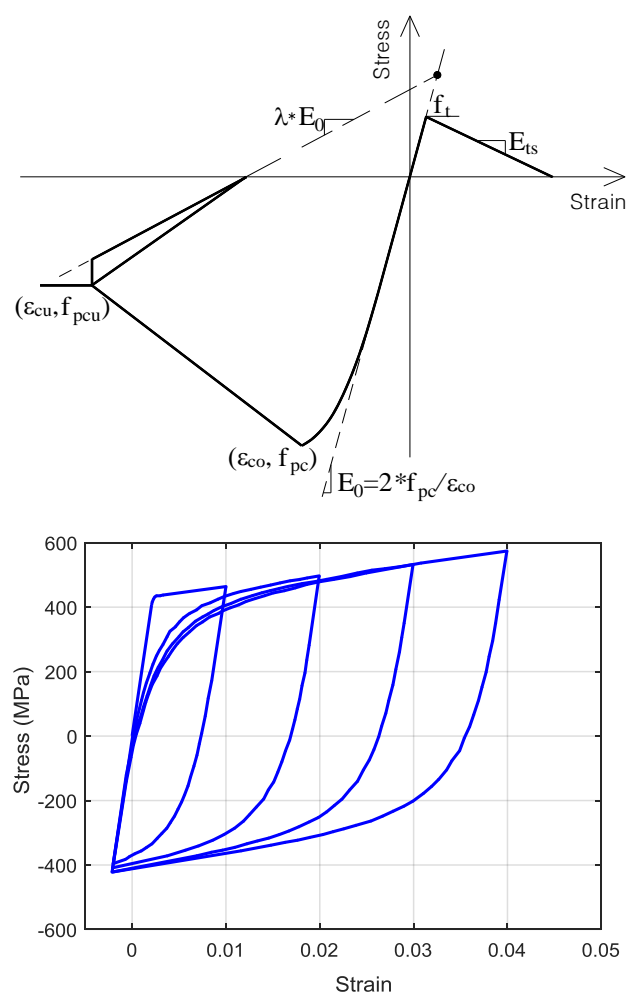

Fig. 3. Material models for concrete and reinforcing bar 


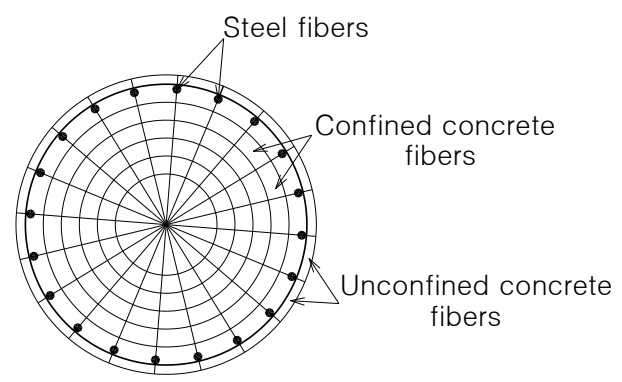

Fiber section modeling of pier

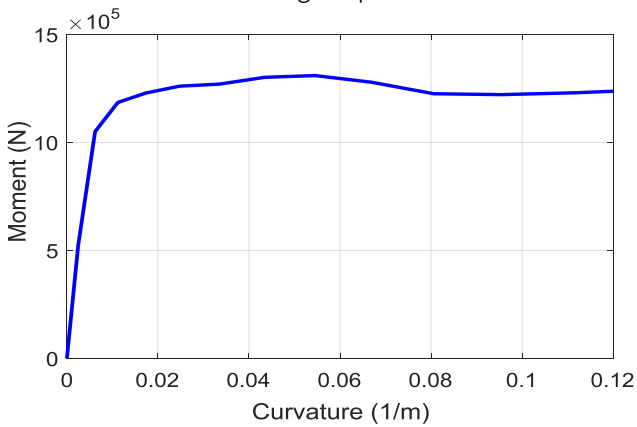

Fig. 4. Fiber section model and moment-curvature relationship of bridge piers

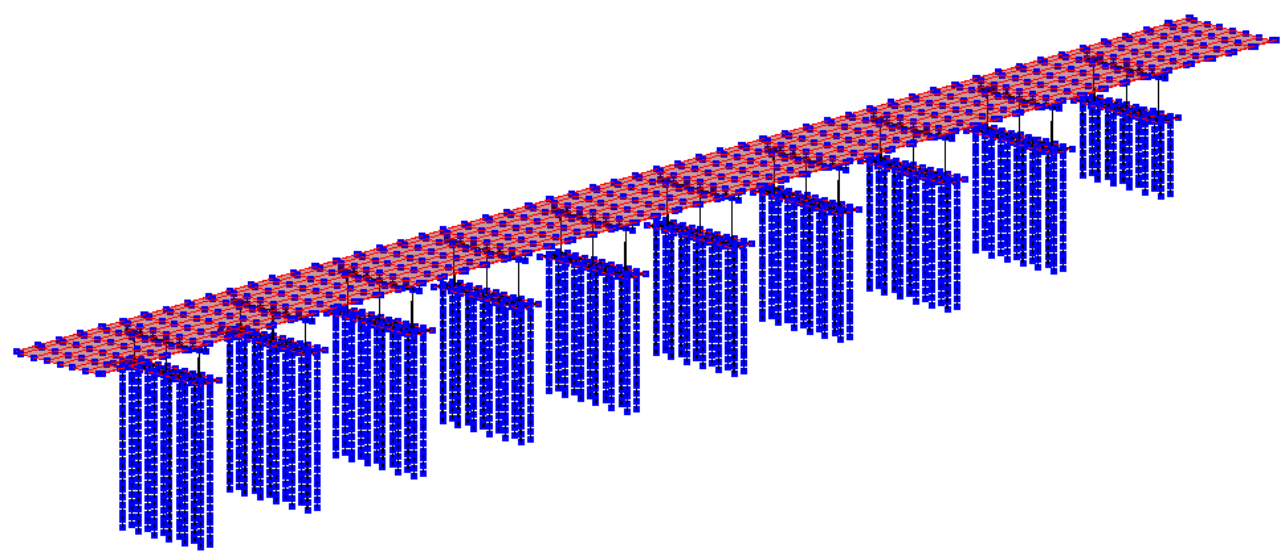

Fig. 5. 3D finite element model of the bridge in OpenSees

\section{Calculation of HCLPF}

This section addresses the procedure of a fragility analysis considering the basis variables (i.e. demand and capacity) as input to obtain the three fragility parameters values. Those parameters are median capacity $\left(A_{m}\right)$, logarithmic standard deviation for randomness $\left(\beta_{r}\right)$ and uncertainty $\left(\beta_{u}\right)$. Consequently, the HCLPF capacity is calculated based on the outcome parameters,

$$
\mathrm{HCLPF}=A_{m * \exp }\left[-1.65\left(\beta_{r}+\beta_{u}\right)\right]
$$


The approximate second moment approach proposed in the EPRI (1994) is adopted to develop fragility parameters of the pier columns. The procedure for fragility analysis of the bridge piers is presented in Fig. 6 .

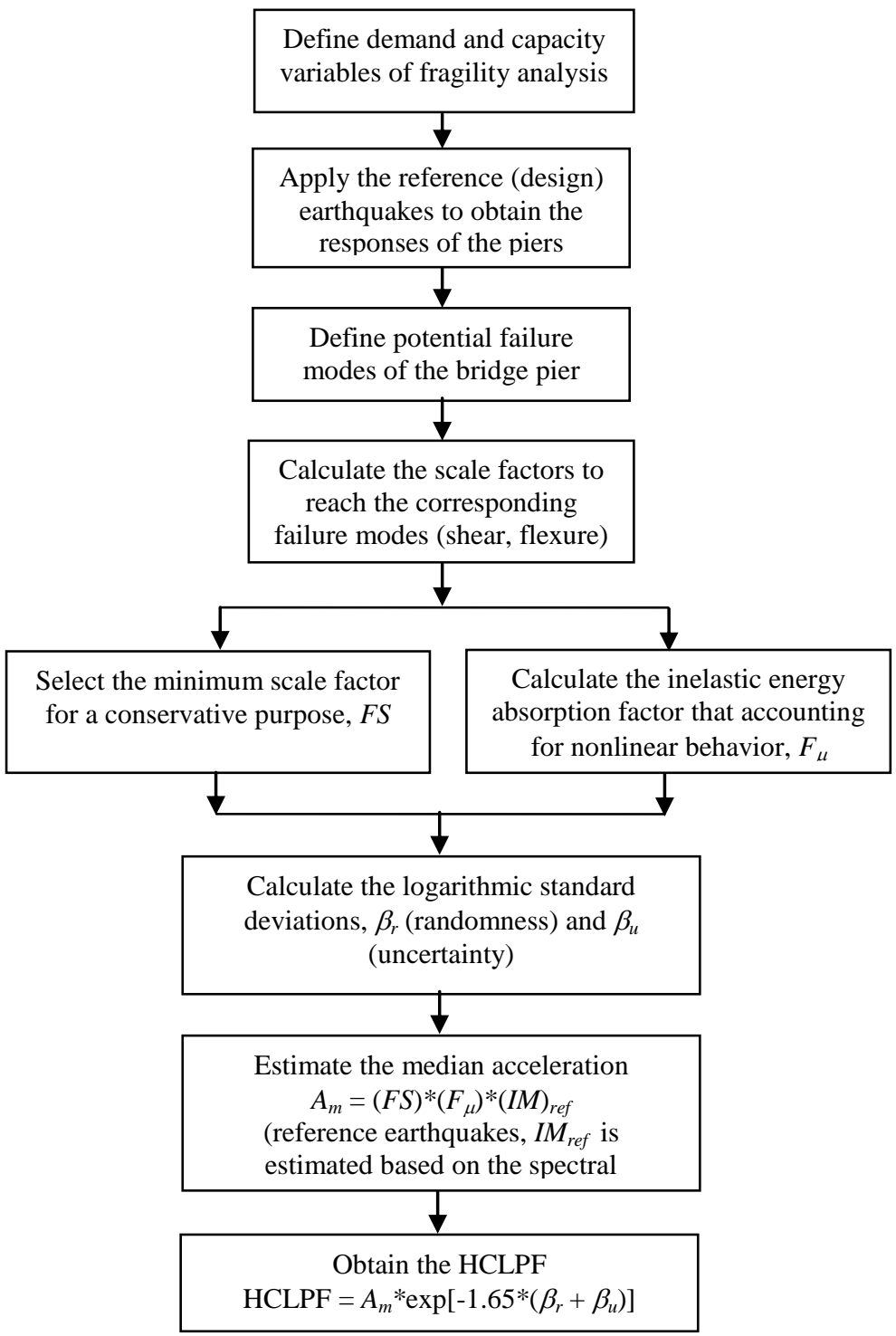

Fig. 6. Flowchart for calculating HCLPF of bridge piers

Table 1. Fragility analysis demand variables

\begin{tabular}{|c|c|c|c|c|}
\hline & Variable & Median demand factor & $\beta_{r}$ & $\beta_{u}$ \\
\hline 1 & Earthquake response spectrum shape & 1.00 & 0.14 & 0.00 \\
\hline 2 & Horizontal direction peak response & 1.00 & 0.13 & 0.00 \\
\hline 3 & Vertical component response & 1.00 & 0.25 & 0.23 \\
\hline 4 & Damping & (median) & 0.00 & 0.03 \\
\hline 5 & Modeling & & & \\
\hline 5.1 & Frequency & 0.70 (median factor) & 0.00 & 0.05 \\
\hline
\end{tabular}




\begin{tabular}{|c|c|c|c|c|}
\hline 5.2 & Mode shape & 1.00 & 0.00 & 0.15 \\
\hline 5.3 & Torsional coupling & 1.15 & 0.00 & 0.05 \\
\hline 6 & Mode combination & 1.00 & 0.15 & 0.00 \\
\hline 7 & Time history simulation & 1.00 & 0.00 & 0.05 \\
\hline 8 & Foundation-structure interaction & & & \\
\hline 8.1 & Ground motion incoherence & 1.05 & 0.00 & 0.05 \\
\hline 8.2 & Vertical spatial variation of GM & 0.70 & 0.08 & 0.00 \\
\hline 8.3 & SSI analysis & 1.00 & 0.00 & 0.10 \\
\hline 9 & Earthquake component combination & 0.40 & 0.15 & 0.00 \\
\hline
\end{tabular}

Table 2. Fragility analysis capacity variables

\begin{tabular}{c|l|cc|c|c}
\hline & \multicolumn{1}{|c|}{ Variable } & \multicolumn{2}{|c|}{ Median capacity factor } & $\boldsymbol{\beta}_{\boldsymbol{r}}$ & $\boldsymbol{\beta}_{\boldsymbol{u}}$ \\
\hline 1 & 28 actual day strength, $f_{c}{ }^{\prime}$ & $2.76 \mathrm{E}+7$ & $\mathrm{~N} / \mathrm{m} 2$ & 0.00 & 0.06 \\
2 & Concrete aging factor & 1.20 & & 0.00 & 0.10 \\
3 & Steel reinforcement yield strength, $f_{y}$ & $4.14 \mathrm{E}+8$ & $\mathrm{~N} / \mathrm{m} 2$ & 0.00 & 0.09 \\
4 & Shear equation error factor, $\Phi_{s}$ & 1.00 & & 0.00 & 0.20 \\
5 & Flexural equation error factor, $\Phi_{f}$ & 1.00 & & 0.00 & 0.15 \\
6 & Drift limit (displacement/height), $D R$ & 0.04 & 0.15 & 0.30 \\
\hline
\end{tabular}

Table 3. Deterministic properties of the bridge pier

\begin{tabular}{c|l|c|c}
\hline & \multicolumn{1}{|c|}{ Property } & Value & Unit \\
\hline 1 & Pier height, $L$ & 6.00 & $\mathrm{~m}$ \\
2 & Pier diameter, $D$ & 0.80 & $\mathrm{~m}$ \\
3 & Pier area, $A_{g}$ & 0.50 & $\mathrm{~m} 2$ \\
4 & Shear area of pier, $A_{v}$ & 0.4509 & $\mathrm{~m} 2$ \\
5 & Moment of inertial of pier, $I$ & 0.0198 & $\mathrm{~m} 4$ \\
6 & Longitudinal reinforcing bar ratio, $\rho_{v}$ & 0.0199 & \\
7 & Transversal reinforcing bar ratio, $\rho_{s}$ & 0.0013 & \\
8 & Axial force due to gravity, $N_{d}$ & $1,091,861$ & $\mathrm{~N}$ \\
9 & Fundamental frequency, $f$ & 2.222 & $\mathrm{~Hz}$ \\
10 & Elastic damping, $\beta$ & 0.05 & \\
\hline
\end{tabular}

A list of the basis demand and capacity variables of fragility analysis is given in Table 1 and Table 2, respectively. Each of these variables and recommended procedures for obtaining their parameter values can be referred in EPRI (1994). Particularly, the drift limit is estimated based on the moment-curvature relationship, in which the curvature of 0.08 (i.e. at the concrete crushing) is considered as the failure state of the piers. The drift limit can be evaluated by following equation according to FHWA (2006) [7],

$$
D R=\Phi^{*} L / 3
$$

where $\Phi$ is curvature and $L$ is the pier height. Table 3 gives a summary of the deterministic properties of the pier for analysis.

Table 4. Seismic fragility analysis results of the bridge piers

\begin{tabular}{c|c|c|c|c|c}
\hline Pier & $\boldsymbol{A}_{\boldsymbol{m}}$ & $\boldsymbol{\beta}_{\boldsymbol{r}}$ & $\boldsymbol{\beta}_{\boldsymbol{u}}$ & $\boldsymbol{\beta}_{c}=\sqrt{\beta_{r}^{2}+\beta_{u}^{2}}$ & HCLPE (g) \\
\hline Pier P1 & 2.335 & 0.298 & 0.260 & 0.396 & 0.929 \\
Pier P2 & 2.263 & 0.298 & 0.261 & 0.396 & 0.901 \\
Pier P3 & 2.871 & 0.297 & 0.260 & 0.395 & 1.145
\end{tabular}




\begin{tabular}{c|l|l|l|l|l} 
Pier P4 & 2.068 & 0.298 & 0.260 & 0.396 & 0.823 \\
Pier P5 & 1.289 & 0.298 & 0.265 & 0.399 & 0.509 \\
Pier P6 & 1.604 & 0.298 & 0.261 & 0.396 & 0.638 \\
Pier P7 & 1.257 & 0.298 & 0.261 & 0.396 & 0.500 \\
Pier P8 & 2.277 & 0.298 & 0.260 & 0.396 & 0.906 \\
Pier P9 & 2.384 & 0.298 & 0.260 & 0.396 & 0.949 \\
Pier P10 & 3.091 & 0.297 & 0.260 & 0.395 & 1.233 \\
\hline
\end{tabular}
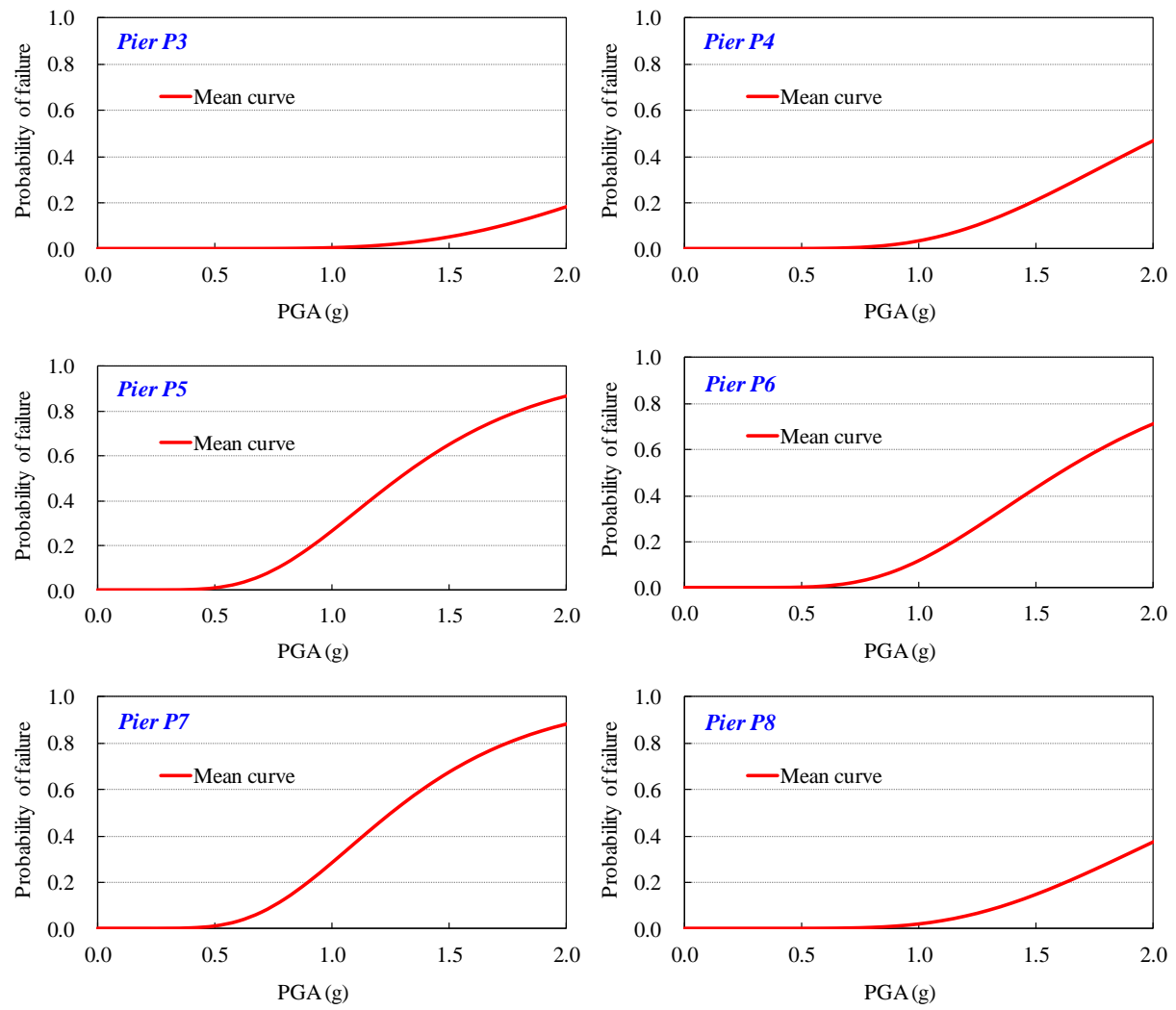

Fig. 7. Composite fragility curves of bridge piers

The results of seismic fragility analysis of all the bridge piers are summarized in Table 4. Note that $\beta_{c}$ in Table 4 is the composite standard deviation and defined as a combination of the randomness $\left(\beta_{r}\right)$ and uncertainty $\left(\beta_{u}\right)$ standard deviations. It can be observed that the minimum value of HCPLF is $0.5 \mathrm{~g}$, larger than the SSE design value, so that the bridge may be safe under earthquakes with PGA less than $0.5 \mathrm{~g}$. Moreover, the piers at the middle area of the bridge (i.e. from P5 to P7) show a higher probability of failure than the ending parts. This is due to the reason that the shear forces induced by the seismic load at the center area of the bridge is larger than those at the others. The composite fragility curves of the bridge piers at the ultimate state are shown in Fig. 7.

\section{Conclusions}

This paper presents a seismic margin assessment of the bridge structure which was built in an NPP in Korea. The HCPLF capacity values of the bridge piers are calculated by 
applying the fragility method in terms of the approximate second moment procedure. The results from fragility analysis emphasize that the piers at the middle part of the bridge (i.e. P5, P6, and P7) can be more vulnerable than the others during earthquakes. The lowest HCPLF capacity of the piers, $0.50 \mathrm{~g}$, is obviously shown to be larger than the current SSE design level for NPP structures in Korea (i.e. 0.3g PGA). However, the 2016 Gyeongju and 2017 Pohang earthquakes occurred in the region showed that the PGA can be larger than $0.5 \mathrm{~g}$, thus, gives an important message to designers on seismic design and retrofitting issues of infrastructures in Korea.

This study is supported by project titled "Development of High Reliability Seismic Monitoring System for Precise Analysis of High Frequency Earthquake Motion in Nuclear Power Plants", assignment number 20171510101860.

\section{References}

1. Kennedy RP (1985). Various types of reported seismic margins and their use. Proceedings of EPRI/NRC Workshop on Nuclear Power Plant Reevaluation to Quantify Seismic Margins, EPRI NP-4101-SR, Electric Power Research Institute, USA.

2. EPRI (1994). Methodology for developing seismic fragilities. Technical report TR103959, Electric Power Research Institute, USA.

3. Mazzoni S, McKenna F, Scott M H and Fenves GL (2007). OpenSees command language manual. Pacific Earthquake Engineering Research Center, University of California, Berkeley USA.

4. Kent DC and Park R (1971). Flexural members with confined concrete. ASCE J. Struct. Div. 97(7), 1969-1990.

5. Menegotto M and Pinto PE (1973). Method of analysis for cyclically loaded reinforced concrete plane frames including changes in geometry and non-elastic behavior of elements under combined normal force and bending. Proceedings of the IABSE Symposium of Resistance and Ultimate Deformability of Structures Acted on by WellDefined Repeated Loads, Lisbon, Portugal.

6. Reese LC, Cox WR, and Koop FD (1974). Field testing and analysis of laterally loaded piles in sand. Proceedings of the VI Annual Offshore Technology Conference, Houston, Texas, p473-485.

7. FHWA (2006). Seismic Retrofitting Manual for Highway Structures: Part 1 - Bridges. Technical report FHWA-HRT-06-032, US Department of Transportation, Federal Highway Administration, McLean, Virginia, USA. 